\title{
The effects of peptide modified gellan gum and olfactory ensheathing glia cells on neural stem/progenitor cell fate
}

\author{
Nuno A. Silva ${ }^{\text {a,b,c,d,e }}$, Michael J. Cooke ${ }^{\text {d,e }}$, Roger Y. Tam ${ }^{\text {d,e }}$, Nuno Sousa ${ }^{\text {b,c }}$, António J. Salgado ${ }^{\text {b,c }}$, \\ Rui L. Reis ${ }^{\mathrm{a}, \mathrm{b}}$, Molly S. Shoichet ${ }^{\mathrm{d}, \mathrm{e}, \mathrm{f}, *}$ \\ a 3B's Research Group - Biomaterials, Biodegradables and Biomimetics, University of Minho, Headquarters of the European Institute of Excellence on Tissue Engineering and \\ Regenerative Medicine, AvePark, Guimarães, Portugal \\ ${ }^{\mathrm{b}}$ ICVS/3B's - PT Government Associated Laboratory, Braga/Guimarães, Portugal \\ ${ }^{c}$ Life and Health Sciences Research Institute (ICVS), School of Health Sciences, University of Minho, Braga, Portugal \\ ${ }^{\mathrm{d}}$ Department of Chemical Engineering and Applied Chemistry, University of Toronto, 200 College Street, Toronto, ON M5S 3E5, Canada \\ e Institute of Biomaterials and Biomedical Engineering, 164 College Street, Room 407, Toronto, ON M5S 3G9, Canada \\ ${ }^{\mathrm{f}}$ Department of Chemistry, University of Toronto, 80 St. George Street, Toronto, ON M5S 3H6, Canada
}

\section{A R T I C L E I N F O}

\section{Article history:}

Received 11 April 2012

Accepted 20 May 2012

Available online 12 June 2012

\section{Keywords:}

Gellan gum

Olfactory ensheathing glia cell

Neural stem/progenitor cell

Spinal cord injury

RGD

Diels-Alder click chemistry

\begin{abstract}
A B S T R A C T
The regenerative capacity of injured adult central nervous system (CNS) tissue is very limited. Specifically, traumatic spinal cord injury (SCI) leads to permanent loss of motor and sensory functions below the site of injury, as well as other detrimental complications. A potential regenerative strategy is stem cell transplantation; however, cell survival is typically less than $1 \%$. To improve cell survival, stem cells can be delivered in a biomaterial matrix that provides an environment conducive to survival after transplantation. One major challenge in this approach is to define the biomaterial and cell strategies in vitro. To this end, we investigated both peptide-modification of gellan gum and olfactory ensheathing glia (OEG) on neural stem/ progenitor cell (NSPC) fate. To enhance cell adhesion, the gellan gum (GG) was modified using Diels-Alder click chemistry with a fibronectin-derived synthetic peptide (GRGDS). Amino acid analysis demonstrated that approximately $300 \mathrm{nmol}$ of GRGDS was immobilized to each $\mathrm{mg}$ of GG. The GG-GRGDS had a profound effect on NSPC morphology and proliferation, distinct from that of NSPCs in GG alone, demonstrating the importance of GRGDS for cell-GG interaction. To further enhance NSPC survival and outgrowth, they were cultured with OEG. Here NSPCs interacted extensively with OEG, demonstrating significantly greater survival and proliferation relative to monocultures of NSPCs. These results suggest that this co-culture strategy of NSPCs with OEG may have therapeutic benefit for SCI repair.
\end{abstract}

(C) 2012 Elsevier Ltd. All rights reserved.

\section{Introduction}

Traumatic spinal cord injury (SCI) usually leads to significant neurological deficits and disabilities that result in loss of sensory and motor function, termed paraplegia or tetraplegia depending on the site of injury. This can subsequently result in other related problems such as infections of the bladder and kidneys and dysfunction of the bowel, as well as heart and respiratory system. All of these problems have a negative effect on the physiological, psychological and social behavior of SCI patients. Current clinical

\footnotetext{
* Corresponding author. University of Toronto, Donnelly Centre for Cellular \& Biomolecular Research, 160 College Street, Room 514, Toronto, Ontario M5S 3E1, Canada. Tel.: +1 416978 1460; fax: +1 4169784317.

E-mail address: molly.shoichet@utoronto.ca (M.S. Shoichet).
}

approaches are limited and mainly based on the use of antiinflammatory agents, such as methylprednisolone [1]; however, its use is controversial as recent studies failed to reveal conclusive beneficial outcomes [2]. Some of the other strategies that have been tested clinically include: minocycline [3], anti-NogoA [4] and transplantation of oligodendrocyte precursor cells [5]. The latter trial was recently canceled, underlying the urgent need to develop therapeutic strategies that can promote regeneration after SCI.

One approach currently under investigation for regeneration following SCI is the transplantation of cells into the spinal cord. Several groups have reported that the injection of cells, such as olfactory ensheathing glia cells (OEG or OECs) [6,7], neural stem/progenitor cells (NSPCs) [8] or mesenchymal stem cells [9,10], leads to motor improvements and/or tissue repair in SCI animal models. OEG are compelling because they support and guide olfactory axons [11], are able to grow through the glial scar [12] and secrete several 
neurotrophic factors [13]. NSPC transplants have shown some functional repair, taking advantage of their ability to differentiate to neurons, oligodendrocytes and astrocytes [14]. However, to date no single repair strategy has successfully induced full functional recovery following SCI. Extensive cell death of the transplanted cells after injection, due to inflammation and/or the absence of matrix support $[15,16]$, has limited the therapeutic benefit. To enhance cell survival, we investigated the co-delivery of two cell types in an engineered matrix where the second cell type provides trophic support and the matrix contributes to overcoming cell death through anoikis [17].

Biomaterials have been designed as vehicles for cell transplantation in order to enhance cell survival after transplantation. Hydrogels are particularly appealing for soft tissue applications because they can be designed to match the mechanical properties and water content of these tissues. For example, delivering NSPCs in chitosan tubular scaffolds demonstrated NSPC survival and promising results for tissue and functional repair [8]. The gellan gum hydrogel is compelling because it can be injected in a minimally-invasive way to form a gel in situ. Gellan gum (GG) is a linear anionic microbial polysaccharide composed of repeating units of glucose, glucuronic acid and rhamnose [18] and thus has multiple hydroxyl groups available for chemical modification. It has been studied for drug delivery and cartilage regeneration [19-21] and is approved by the FDA as a food additive.

In order to better mimic the extracellular matrix (ECM), biomaterials have been modified with several peptide sequences [22-24] to influence biological processes, such as cell adhesion, growth and development $[25,26]$. Cells transplanted in a material that mimics both the mechanical and chemical properties of native tissue have been shown to be more efficacious after transplantation $[27,28]$.

Here we aim to synthesize GG with enhanced cell-ECM and cell-cell interactions for ultimate use in cell transplantation. To promote cell survival and interaction with gellan gum, we chemically conjugated the fibronectin-derived peptide sequence GRGDS via Diels-Alder click chemistry and studied the impact of GRGDSmodified gellan gum (GG-GRGDS) on cell fate. To enhance cell survival beyond that provided by the ECM-mimetic peptide sequence, cell-cell interactions are investigated. Since OEG have been shown to provide guidance pathways to axons and NSPCs have been shown to promote some functional recovery, we investigated the co-culture of these two cell types to determine whether OEG affected NSPC survival and/or differentiation. To gain a greater appreciation of the OEG-NSPC interaction, the two cell types were cultured in direct contact, in a transwell system or in the GG-GRGDS. Importantly, both OEG and NSPCs can be isolated from human patients $[29,30]$, which enhance the eventual feasibility of this therapeutic strategy for SCI.

\section{Materials and methods}

\subsection{Synthesis of furan-modified gellan gum hydrogel}

Gellan gum (Sigma, USA) was first dissolved in 2-(N-morpholino)ethanesulfonic acid (MES) buffer (100 mM, pH 5.5) at $37^{\circ} \mathrm{C} .4$-(4,6-Dimethoxy-1,3,5-triazin-2-yl)-4methylmorpholinium chloride (DMT-MM, Sigma, USA) and furfurylamine (Acros Organics, Belgium) were then added in a $4: 1 \mathrm{~m}$ ratio (of each reagent relative to the $-\mathrm{COOH}$ groups in gellan gum) and stirred at $37{ }^{\circ} \mathrm{C}$ for $48 \mathrm{~h}$. The solution was then dialyzed ( $M_{\mathrm{W}}$ cutoff $12-14 \mathrm{kDa}$, Spectrum Labs, USA) alternately against distilled water and $\mathrm{PBS}(0.1 \mathrm{M}, \mathrm{pH} 7.2)$ for 5 days. Finally, water was removed by lyophilization to obtain furan-modified gellan gum (furan-GG) as a white powder. ${ }^{1} \mathrm{H}$ NMR spectra were used to analyze the degree of furan substitution. ${ }^{1} \mathrm{H}$ NMR was recorded in $\mathrm{D}_{2} \mathrm{O}$ on a Varian Mercury-400MHz NMR spectrometer (Palo Alto, USA). As a negative control, GG was incubated with furfurylamine in the absence of DMT-MM.

\subsection{Synthesis of maleimide-modified GRGDS peptide}

Maleimide-modified GRGDS (mal-GRGDS) peptide was prepared by linear solidphase synthesis (SPS) using standard Fmoc chemistry [31]. Fmoc-serine Wang resin
(Anaspec, USA) with a loading capacity of $0.48 \mathrm{mmol} / \mathrm{g}$ was swollen in DMF (Sigma, USA) for $30 \mathrm{~min}$. The solution was then drained and a solution of $20 \%$ piperidine (Caledon, Canada) in DMF was added and mixed for $30 \mathrm{~min}$. The resin was then washed with DMF and tested for free amines using $1 \%$ trinitrobenzenesulfonate TNBS (TCI America, USA), in DMF. The first amino acidbuilding block (Fmoc-Asp-OH, 3.0 equivalents, NovaBiochem) was pre-mixed with 2-(6-chloro1H-benzotriazole-1-yl)-1,1,3,3-tetramethylaminium hexafluorophosphate, HCTU (3.0 equivalents, Anaspec, USA) in DMF for $15 \mathrm{~min}$, then transferred to the SPS flask. $1.0 \mathrm{~m}$ diisopropylethylamine, (DIPEA, 4.0 equivalents, Sigma, USA) in DMF was then added and the flask was stirred until the coupling reaction was complete, which was determined by the TNBS test (negative test outcome). The Fmoc deprotection and coupling steps were repeated until five amino acid residues (GRGDS) were coupled to the resin. To conjugate the maleimide linker to the deprotected $\mathrm{N}$-terminus of the peptide, 4 equivalents of maleimidopropionic acid (TCI America, USA) and 12 equivalents of diisopropylcarbodiimide (Sigma, USA) were pre-mixed in dichloromethane for $45 \mathrm{~min}$ and then added to the SPS flask and stirred for $24 \mathrm{~h}$. The maleimide-modified GRGDS (mal-GRGDS) sequence was then cleaved from the resin using 95\% trifluoroacetic acid (Caledon, Canada) in water. The peptide was allowed to precipitate in cold diethyl ether for $30 \mathrm{~min}$. Then, the precipitate was recovered by centrifugation. Finally, the product was purified by HPLC (Shimadzu, Japan) in a C18, $250 \times 10 \mathrm{~mm}, 5 \mathrm{um}, 100 \AA$ A column. A mobile phase gradient from $5 \%$ to $20 \%$ (Acetonitrile (with $0.1 \%$ TFA): $\mathrm{ddH}_{2} \mathrm{O}$ (with $0.1 \% \mathrm{TFA}$ ) ) over 30 min was performed. A $90 \%$ yield was obtained and the product was confirmed by ${ }^{1} \mathrm{H}$ NMR and mass spectrometry (MS).

2.3. Immobilization of mal-GRGDS peptide on furan-GG hydrogel by Diels-Alder chemistry

Immobilization of maleimide-containing GRGDS (mal-GRGDS) to furanmodified gellan gum was performed via Diels-Alder chemistry between the maleimide functional group of the peptide with the furan group of the gellan gum. Furan-GG was first dissolved in MES buffer $(100 \mathrm{~mm}, \mathrm{pH} 5.5)$ at $37^{\circ} \mathrm{C}(4 \mathrm{mg} / \mathrm{ml})$ Mal-GRGDS was then added in a 5:1 maleimide:furan molar ratio and vigorously stirred for $48 \mathrm{~h}$. The solution was then dialyzed $\left(M_{\mathrm{w}}\right.$ cutoff $\left.12-14 \mathrm{kDa}\right)$ alternately against distilled water and PBS $(0.1 \mathrm{M}, \mathrm{pH} 7.2)$ for 5 days. Finally, the water was removed by lyophilization to obtain GRGDS-modified Gellan Gum (GG-GRGDS) as a white powder. The amount of peptide immobilized on the hydrogel was calculated by amino acid analysis. In brief, this method involved acid hydrolysis of the peptide with $6 \mathrm{~N} \mathrm{HCl}$ for $24 \mathrm{~h}$, followed by derivatization with phenylisothiocyanate (PITC). The derivatized hydrolyzates were then quantified using reverse phase HPLC. As a negative control, mal-GRGDS was incubated with unmodified gellam gum.

\subsection{Cell isolation and culture}

All animal work was carried out in accordance with the Guide to the Care and Use of Experimental Animals (Canadian Council on Animal Care) and approved by the Animal Care Committee at the University of Toronto. Neural stem/progenitors cells were isolated from the subependymal region of the lateral ventricles in the forebrain of 6-8 weeks old male Wistar rats as previously described [32]. Cells were grown in neurobasal medium (Invitrogen, Canada), with 2\% of B27 neural supplement (Invitrogen), 1\% of L-glutamine (Sigma), 1\% of penicillin-streptomycin (Sigma), $20 \mathrm{ng} / \mathrm{ml}$ EGF (recombinant human EGF; Invitrogen), $20 \mathrm{ng} / \mathrm{ml}$ bFGF (recombinant human bFGF; Invitrogen) and $2 \mathrm{ng} / \mathrm{ml}$ heparin (Sigma). Cell number and viability were determined with a hemocytometer using the trypan blue exclusion test Dissociated cells were plated in complete media and incubated in a humidified atmosphere at $37{ }^{\circ} \mathrm{C}$ with $5 \%$ of $\mathrm{CO}_{2}$. Neurospheres were observed within $1-2$ weeks, after which cells were passaged weekly.

Olfactory ensheathing cells were isolated from adult male Wistar rats as previously described [33]. Briefly, upon the olfactory bulb dissection all meninges were removed and the tissue was digested with $0.125 \%$ collagenase type I (Sigma) for $20 \mathrm{~min}$ at $37^{\circ} \mathrm{C}$. The digested tissue was mechanically dissociated with a pipette and then filtered through a $40 \mu \mathrm{m}$ cell strainer (BD Falcon, USA). After centrifugation at $1000 \mathrm{rpm}$ for $10 \mathrm{~min}$, cells were resuspended and plated in uncoated plates for $18 \mathrm{~h}$ A posterior change to new uncoated plates for $36 \mathrm{~h}$ was made, as it is expected that most of the fibroblasts and astrocytes will attach in the first and second period, respectively. Finally, the cell suspensions were transferred to fibronectin treated flasks (coated overnight with $1 \mu \mathrm{g} / \mathrm{ml}$ fibronectin solution, (Sigma, USA) and cultured in DMEM/F12 (Gibco) with $10 \%$ of FBS (Gibco) and $1 \%$ of antibiotic-antimycotic solution (Sigma) at $37^{\circ} \mathrm{C}$ and $5 \% \mathrm{CO}_{2}$. OEG were enriched by the supplementation with Bovine Pituitary Extract ( $5 \mu \mathrm{g} / \mathrm{ml}$, Gibco) and Forskolin (2 $\mu \mathrm{g} / \mathrm{ml}$, Sigma).

\subsection{Neural stem/progenitors cell culture on GRGDS-modified gellan gum}

Bioactivity of GG-GRGDS was assessed by the analysis of NSPC growth, morphology and differentiation when cultured on the hydrogel for 2 and 7 days. NSPCs were mechanically dissociated into a single cell suspension and either seeded on the surface or encapsulated into GG-GRGDS hydrogel in complete medium (as described in Section 2.1). The cell density was $2 \times 10^{4}$ cells $/ \mathrm{cm}^{2}$ and hydrogels were 
incubated in a humidified atmosphere at $37^{\circ} \mathrm{C}$ and $5 \%$ of $\mathrm{CO}_{2}$. Furan-modified GG was used as a control. Cell growth and morphology was evaluated by phalloidin DAPI staining and differentiation was evaluated using immunocytochemistry (ICC). Analysis was carried out using a Zeiss Observer Z1 microscope with a Yokogawa confocal scan unit; images were captured and processed using Volocity 4.3.2 software.

\subsection{Co-cultures between OEG and NSPCS}

To evaluate the potential synergistic or antagonistic effects between OEG and NSPCs, direct and transwell co-culture experiments were performed. OEC $\left(1 \times 10^{5}\right.$ cells $\left./ \mathrm{cm}^{2}\right)$ and NSPCs $\left(4 \times 10^{4}\right.$ cells $\left./ \mathrm{cm}^{2}\right)$, obtained as described in section 2.4 , were seeded either simultaneously onto the same fibronectin-coated cover glass, or in indirect contact by using a transwell (with OEG cultured on the fibronectin-coated cover glass and NSPCs on the transwell). Cells were allowed to grow in complete NSPC culture medium (see section 2.4) for $24 \mathrm{~h}$ and then cultured in the absence of the growth factors, FGF2 and EGF. In the direct co-culture experiment, in order to clearly identify one cell population from another, OEG were labeled (according to manufacturer instructions) with a cell tracing reagent (C34554, Invitrogen) before seeding. After 7 days of incubation, cell growth and NSPC differentiation was assessed by ICC. Analysis was performed using an Olympus BX61fluorescence microscope. OEG and NSPCs cultured alone were used as controls

After these initial experiments, OEG and NSPCs were then encapsulated together in the GG-GRGDS hydrogel. Both cells were pre-labeled before encapsulation. A green tracer was used for OEG labeling (C34554, Invitrogen) and NSPCs were labeled with a far red tracer (C34553, Invitrogen). Both labeling protocols were performed according to the manufacturer instructions. Cell interactions and growth were then analyzed by confocal analyses after 7 days of culture.

\subsection{Immunocytochemistry and phalloidin/DAPI staining}

The following primary antibodies were used for the immunocytochemical studies: monoclonal rabbit anti- $\beta$-III tubulin (1:500, Chemicon, Canada) for neurons; monoclonal mouse anti-GFAP (1:100, Chemicon) for astrocytes; monoclonal mouse anti-O4 (1:200, R\&D Systems, Canada) for oligodendrocytes; monoclonal mouse anti-Nestin (1:100, Millipore, USA) for progenitor cells; and polyclonal rabbit anti-p75 (1:100, Millipore) for OEG. For all immunocytochemical procedures, the appropriate controls were obtained by omission of the relevant primary antibody. Cells on the substrates were fixed with PBS solution containing $4 \%$ paraformaldehyde PFA for $20 \mathrm{~min}$ (on glass) or $1 \mathrm{~h}$ (in the hydrogel) at room temperature and then washed with PBS. Next, cell membrane permeation (except for p75 and 04 antibodies) and blocking by treating cells with $0.3 \%$ TritonX-100 (Sigma, USA) and $10 \%$ of FBS solution at room temperature for $1 \mathrm{~h}$, each specific primary antibody solution was added for $1 \mathrm{~h}$ (on glass) or $12 \mathrm{~h}$ (on hydrogel). After washing with $0.5 \%$ of FBS in PBS, the samples were exposed to the specific secondary antibody (1:500 dilution of Alexa Fluor 488 anti-rabbit and 1:500 dilution of Alexa Fluor 594 anti-mouse, Invitrogen) for $1 \mathrm{~h}$ (on glass) or $5 \mathrm{~h}$ (on hydrogel) and then washed with $0.5 \%$ FBS. Finally, cell nuclei were counterstained with $1 \mu \mathrm{g} / \mathrm{ml}$ DAPI (Invitrogen) for $1 \mathrm{~h}$.

For phalloidin/DAPI staining, cells were fixed with $4 \%$ of PFA for $30 \mathrm{~min}$ at room temperature and then treated with $0.3 \%$ TritonX-100. After washing several times with PBS, $0.1 \mu \mathrm{g} / \mathrm{ml}$ of phalloidin (Sigma) was added to the cells for $30 \mathrm{~min}$. Finally, cell nuclei were counterstained with DAPI ( $1 \mu \mathrm{g} / \mathrm{ml}$, Invitrogen $)$ for $10 \mathrm{~min}$.

\subsection{Statistical analysis}

All statistical analyses were performed using GraphPad Prism version 5.00 for Windows (GraphPad Software, USA). Differences among groups were assessed by two-way ANOVA followed by a Bonferroni post-hoc test (proliferation and differentiation analyses of NSPCs) and by t-student test (proliferation analyses of NSPCs and OEG in the co-cultures experiments). A $p$-value of $\leq 0.05$ (95\% confidence level) was set as the criteria for statistical significance. All data are presented as mean \pm standard deviation.

\section{Results}

\subsection{Synthesis and characterization of GG-GRGDS hydrogel}

Immobilization of the synthetic peptide (mal-GRGDS) to the gellan gum (GG) hydrogel was achieved in two synthetic steps (Fig. 1A). First, the carboxylic acid groups of the glucuronic acid monosaccharide of GG were activated with DMT-MM, and then conjugated to furfurylamine to functionalize the GG with a furan. By ${ }^{1} \mathrm{H}$ NMR analysis, the degree of furan substitution to GG was calculated to be $27 \%$ (Fig. 1B). This was calculated by comparing the ratio of the areas under the furan peaks at $6.26,6.46$ and $7.65 \mathrm{ppm}$ to the methyl peak at $1.2 \mathrm{ppm}$ (of the rhamnose monosaccharide of GG). To confirm that the furfurylamine was covalently bound to GG, and not simply adsorbed, a control reaction (in the absence of the coupling agent, DMT-MM) was similarly characterized, and analysis of this ${ }^{1} \mathrm{H}$ NMR spectrum did not show any furan peaks (Fig. 1C). Second, the furan-GG hydrogel was reacted with maleimidemodified GRGDS peptide to yield GG-GRGDS hydrogel. After excessive dialysis to remove unbound peptide, quantification by amino acid analysis of the immobilized peptide was calculated to be $304.0 \mathrm{nmol}$ of GRGDS peptide per mg of GG (Fig. 1D). A control reaction (using unmodified GG) was also performed to determine the amount of unbound peptide adsorbed on the hydrogel. In the absence of furan substitution to GG, only $5.3 \mathrm{nmol}$ of GRGDS/mg of GG (Fig. 1E) was detected. Thus, approximately $300 \mathrm{nmol} / \mathrm{mg}$ of GRGDS peptide was covalently bound to the GG by the Diels-Alder $[4+2]$ cycloaddition.

\subsection{Biological effect of GG-GRGDS on NSPCS}

NSPCs were either seeded on the surface or encapsulated within GG-GRGDS and compared to NSPCs cultured with unmodified GG hydrogels. Cell proliferation, morphology and differentiation were assessed after 2 and 7 days of culture. The results revealed pronounced differences in NSPC behavior when cultured in the peptide-modified hydrogel relative to the unmodified hydrogel. In the presence of immobilized GRGDS, the cells were able to migrate and successfully expand throughout the hydrogel whereas in the absence of GRGDS, NSPCs interacted preferentially with each other, forming cell aggregates or neurospheres (Fig. 2). Visible cytoplasmatic extensions were observed in the GG-GRGDS, both on the surface (Fig. 2A) and inside the gel (Fig. 2B), but not in the unmodified GG. Moreover, proliferation (number of singles cells between days 2 and 7) and morphological analyses revealed that in the absence of peptides, the cells were only able to proliferate as neurospheres whereas in the GG-GRGDS hydrogel, cells proliferated as single cells. This observation reflects the interaction of NSPCs with GRGDS peptides and their lack of interaction with the GG hydrogel. To quantify this observation, the number of single cells found either encapsulated within or on the gel surface was quantified (Fig. 3A and B): after 7 days of culture, we observed an average of $11.8 \times 10^{4} \pm 5.1 \times 10^{4}$ single cells $/ \mathrm{cm}^{2}$ on the GG-GRGDS gel surface whereas only $7.8 \times 10^{3} \pm 4.2 \times 10^{3}$ single cells $/ \mathrm{cm}^{2}$ on the GG surface. A similar trend was observed with encapsulated cells. The number of single cells in the GG-GRGDS hydrogel of $8.1 \times 10^{4} \pm 2.3 \times 10^{4}$ single cells $/ \mathrm{cm}^{2}$ was significantly higher than that in the GG hydrogel of $8.2 \times 10^{3} \pm 7.3 \times 10^{3}$. Interestingly, while GRGDS modification influenced the number of single cells present, it did not affect the differentiation profile, which was not significantly different (Fig. 3C). After 7 days, the majority of NSPCs on GG-GRGDS and GG hydrogels were $\mathrm{O} 4$ positive oligodendrocytes (72 $\pm 11 \%$ and $64 \pm 30 \%$, respectively) with relatively little differentiation into astrocytes $7 \pm 12 \%$ vs. $0 \pm 0 \%$ and no differentiation into neurons. Moreover, as judged by the nestin expression, approximately one third of the NSPCs remained as progenitors $(32 \pm 16 \%$ vs. $36 \pm 19 \%)$.

\subsection{Co-culture of OEG and NSPCS}

The interaction of OEG and NSPCs was analyzed after 7 days in culture for cell proliferation, and differentiation as a function of direct contact or indirect contact (i.e. same media, but no contact through use of a transwell). Interestingly, the differentiation profile of NSPCs was not altered by the presence of OEG (Fig. 4A); however, NSPCs proliferated significantly more when co-cultured with OEG vs. alone. There was a 2.3 fold increase in the number of NSPCs 

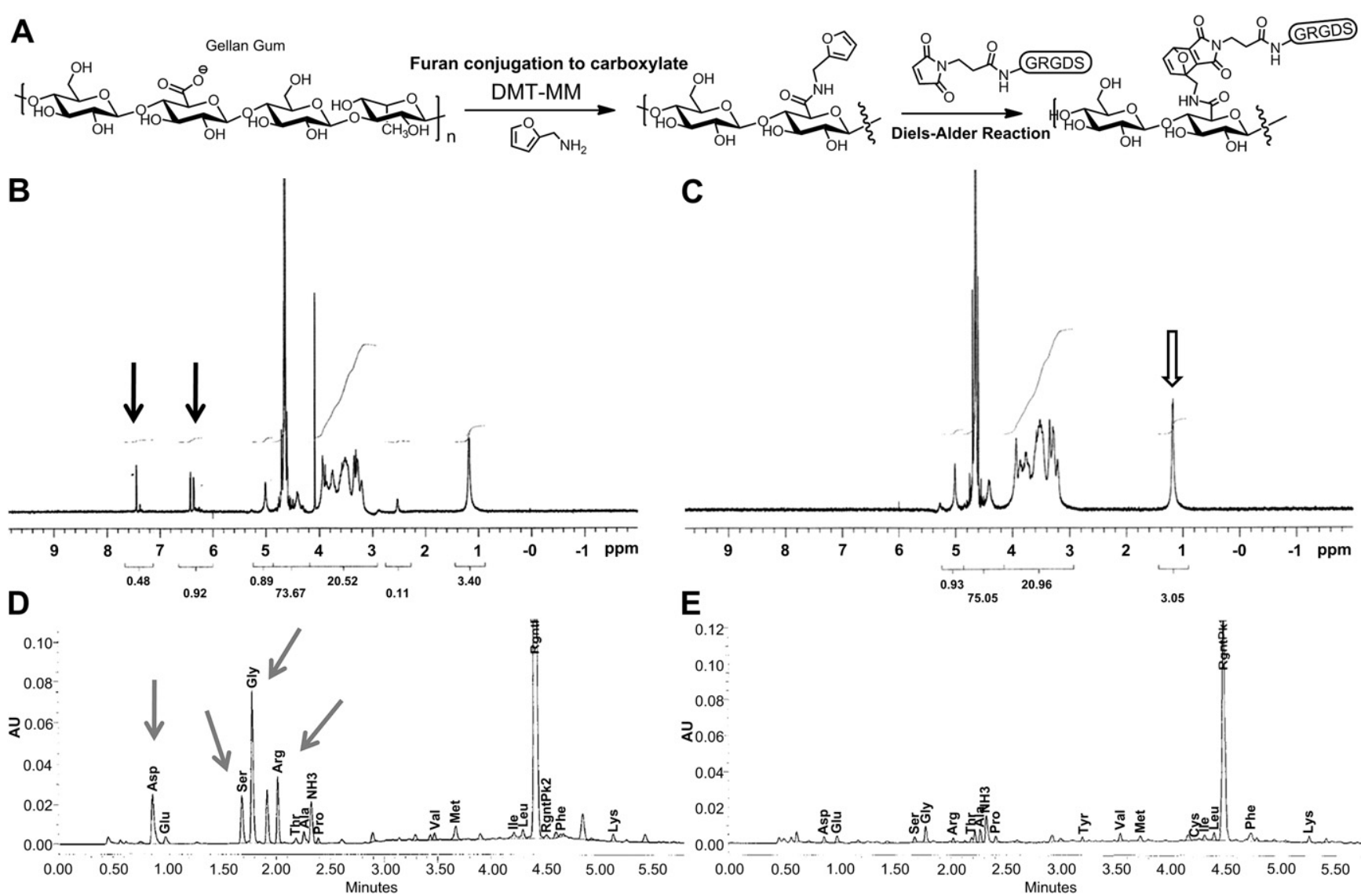

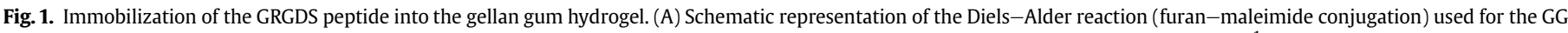

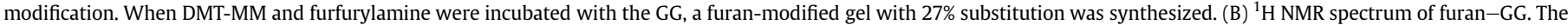

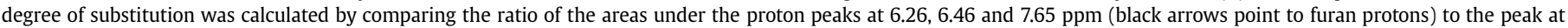

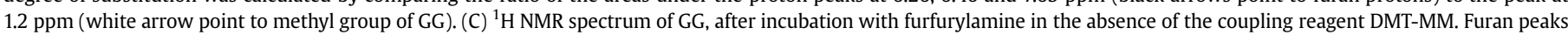

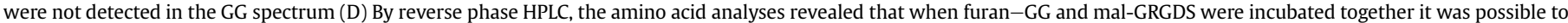

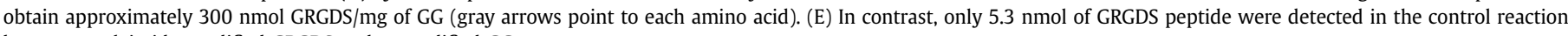
between maleimide-modified GRGDS and unmodified GG.

when co-cultured in direct contact with OEG vs. NSPCs alone (Fig. 4B) and a 1.8-fold increase in the number of NSPCs when cocultured indirectly in transwells with OEG vs. NSPC monocultures (Fig. 4C). These results suggest that OEG secrete factors that enhance NSPC proliferation and that the cells do not need to be in contact in order for this affect to be observed. Unlike the proliferative effect that the OEG had on the NSPCs, the reverse was not true: the total number of OEG was not significantly affected by coculture with NSPCs either in direct contact (Fig. 4D) or indirect, transwell (Fig. 4E) contact. Notwithstanding that OEG do not have to be in direct contact with NSPCs to influence their proliferation, immunocytochemistry illustrates that OEG are closely associated with NSPCs when co-cultured together (Fig. 5). By pre-labeling OEG green with CFSE34554 and counterstaining NSPCs with either nestin (red for progenitors) or $\mathrm{O} 4$ (red for oligodendrocytes), the two cell types appeared to be closely associated with each other. These data suggest that OEG may be able to provide a guidance pathway for NSPC growth.

\subsection{Co-culture of OEG and NSPCs in the GG-GRGDS hydrogel}

To gain greater insight into the interactions of OEG and NSPCs, they were co-cultured together in the 3D gellan gum hydrogel modified with the cell-adhesive peptide, GRGDS (GG-GRGDS). We initially seeded $10^{5}$ OEG and $4 \times 10^{4}$ NSPCs. Different cellular densities were used because NSPCs have a higher proliferative rate than OEG. After 7 days we estimated that both should be near confluence. To facilitate identification, the OEG were pre-labeled green with CFSE34554 and the NSPCs red with DDAO-SE 34553 prior to encapsulation in the GG-GRGDS hydrogel. As was observed in the 2D co-culture study, the total number of NSPCs was significantly higher when co-cultured with OEG than when cultured alone (Fig. 6A). Similar to the 2D data presented in Fig. 4, the number of OEG was unaffected by the presence of NSPCs (Fig. 6B).

\section{Discussion}

Gellan gum (GG) is a natural biomaterial that has shown promise for tissue regeneration. It is a thermo-reversible gel that was previously shown to be cytocompatible with adipose stem cells, rabbit articular chondrocytes and immortalized oligodendrocytes [20,34]. Until recently, most of the research on GG modification was focused on controlling its mechanical properties through gel network formation $[21,35]$. To the best of our knowledge, there is no literature describing the chemical modification of GG with ECM-derived peptides, even though the cellular microenvironment is defined, in part, by its chemical nature. In order to create a hydrogel which mimics the chemical nature of the ECM, bioactive peptides were conjugated to GG, thereby providing a more suitable environment for encapsulated cells to survive and migrate. 

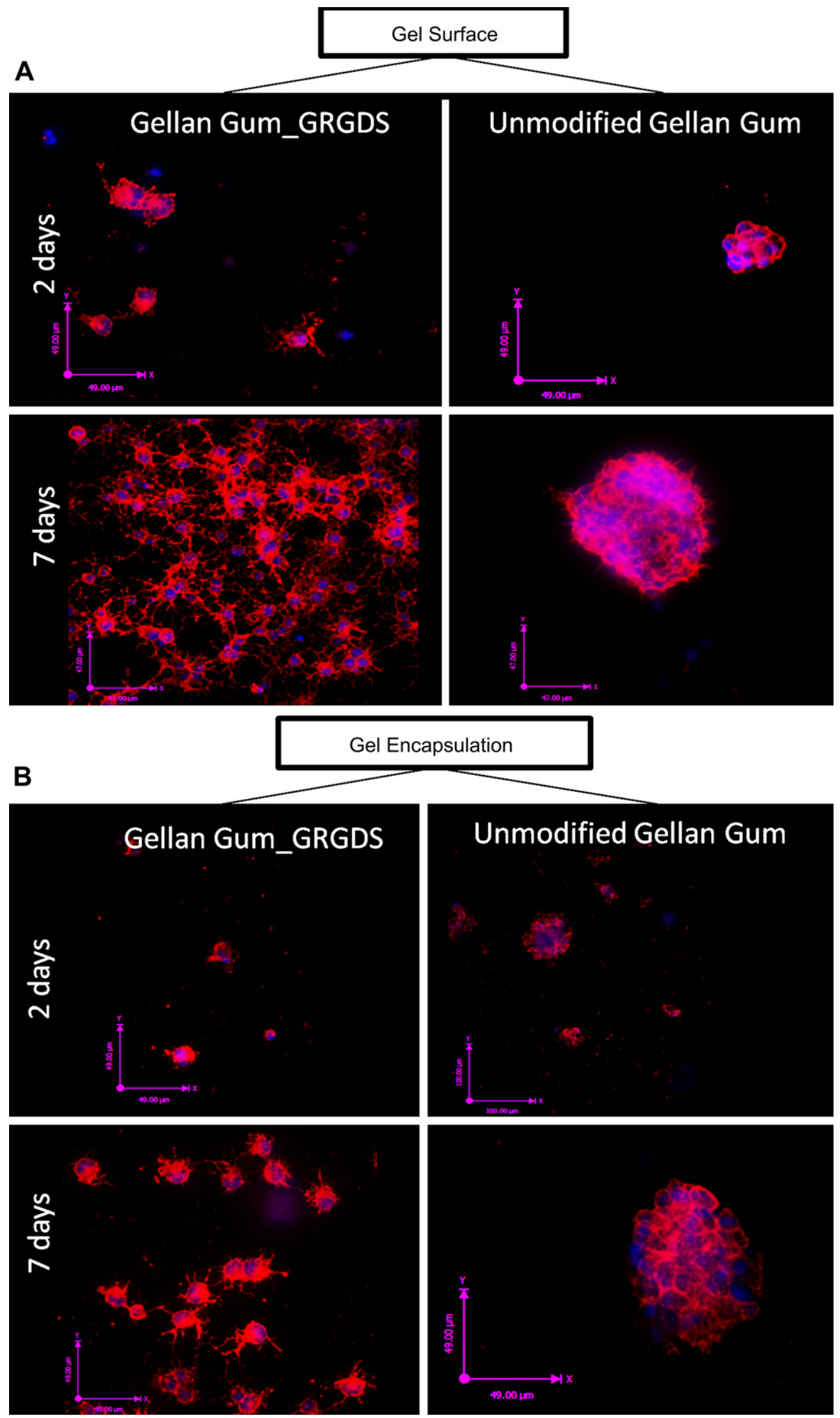

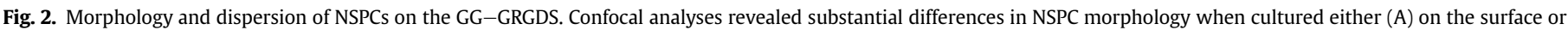

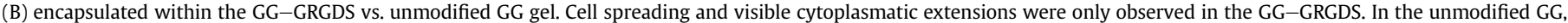

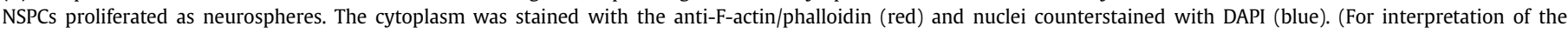
references to color in this figure legend, the reader is referred to the web version of this article.) 
NSPCs Proliferation
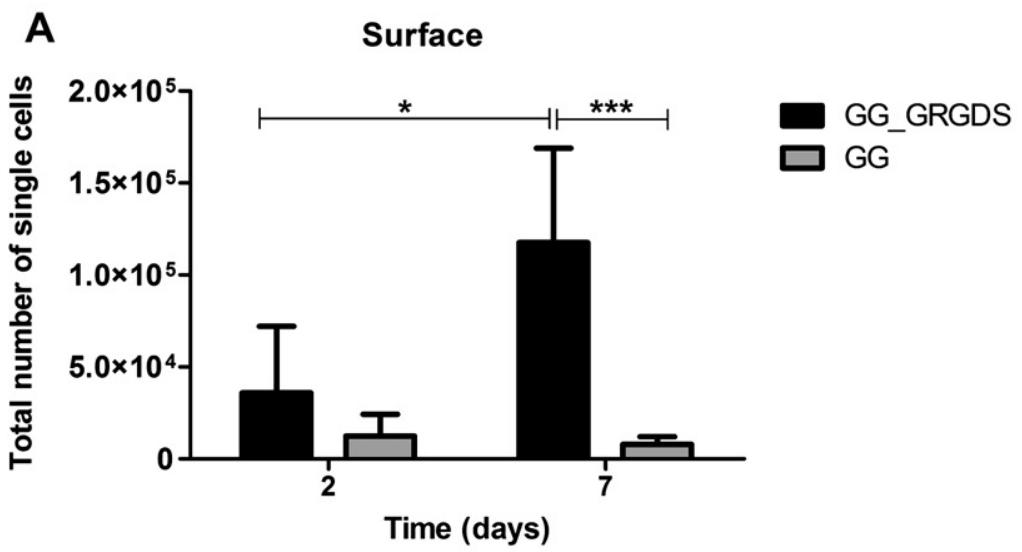

B Encapsulation

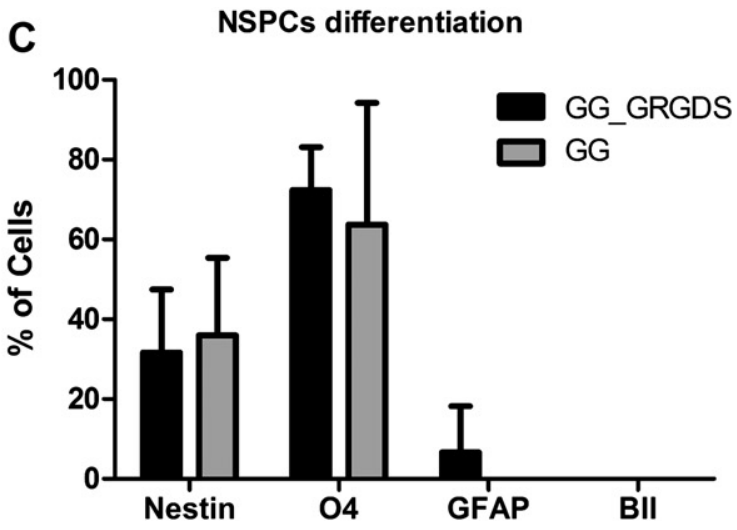

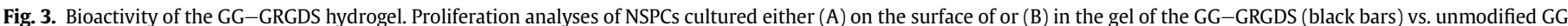

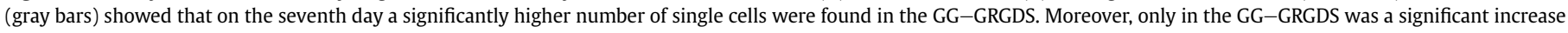

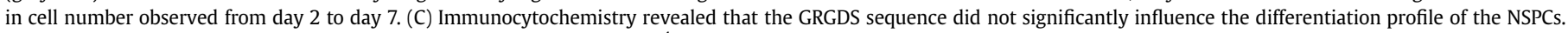
Values are shown as mean \pm standard deviation $\left(n=3\right.$ samples of $2 \times 10^{4}$ cells/sample, $\left.{ }^{*} p<0.05 ;{ }^{* * *} p<0.001\right)$.

The peptide sequence GRGDS is a ubiquitous cell-adhesive peptide, which has been shown to enhance cell-biomaterial interactions, support cell survival and influence cell morphology [22,36]. In this work we show that it is possible to immobilize the GRGDS peptide to GG. By taking advantage of the Diels-Alder click cycloaddition reaction between chemically modified GG-furan and maleimideGRGDS, GG-GRGDS was synthesized in aqueous conditions.

Immobilization of GRGDS to GG had a profound effect on NSPC morphology, distinct from that observed on NSPCs in unmodified GG alone, demonstrating the importance of GRGDS for cell-GG interaction. Importantly, these morphological differences were observed both within the 3D hydrogels and on their surfaces. Unlike most studies that focus only on cells cultured on surfaces, herein we cultured cells both on the hydrogel surface and encapsulated within [36,37]. Given that the ultimate goal involves cell transplantation via an injectable hydrogel, it was reassuring that the cell morphology in 3D mirrored that in 2D. The NSPCs were able to adhere to and extend processes within the GG-GRGDS hydrogel, yet their differentiation profile was not affected by the presence of GRGDS. This reflects the cell-adhesive property ascribed to GRGDS and not a differentiation property. To achieve preferential differentiation to a given phenotype, GG would typically require further modification with growth factors, such as PDGF-AA for oligodendrocytes [38] or interferon-gamma for neurons [39].

The co-culture experiments of NSPCs and OEG, in direct contact or in the transwell, suggested that diffusible factors are responsible for the effects observed. OEG have been shown to secrete several neurotrophic factors including: nerve growth factor (NGF), brain- derived neurotrophic factor (BDNF), glial-derived neurotrophic factor (GDNF) [13], basic fibroblast growth factor (FGF2) and neurotrophin-3 (NT-3) [40]. This rich profile of secreted neurotrophins from OEG may explain the proliferation of NSPCs that we observed in our co-culture studies. For example, NGF and FGF promote NSPC proliferation [41,42]; and NT-3 enhances their survival [43]. The combination of both mechanisms, survival and proliferation, may explain the increased number of NSPCs in all of the co-culture studies.

Other than this study, very little is known about the effects of OEG on the behavior of NSPCs. Interestingly, Cao et al. [33], also observed that OEG promoted NSPC proliferation, yet they also observed increased neurogenesis and oligodendrogenesis of NSPCs cultured with OEG. Differences in the co-culture experiments may account for this discrepancy. Cao et al. harvested the NSPCs from newborn mice, whereas we obtained NSPCs from adult rats; moreover, they co-cultured the cells for only 3 days in DMEM with F12 and N2 supplements whereas we co-cultured the cells for 7 days in neurobasal medium with B27 supplements.

The immunocytochemistry figures suggest that OEG and NSPCs interact with each other. This interaction may be attributed to OEG expressing cell-adhesive molecules, such as N-CAM and L1 [44], and NSPCs expressing the corresponding receptors [45]. The cellular interactions may suggest a role for co-transplantation of OEG and NSPCs.

Cell transplantation has been pursued for several years for $\mathrm{SCI}$ repair. Both OEG and NSPCs have been investigated independently, each with some success. Notably, biomaterial scaffolds have been 
shown to enhance cell survival after transplantation. For example, Cummings et al. [46] showed that transplanting human NSPCs in SCI mice led to some locomotor recovery and remyelination. Johnson et al. [47] demonstrated that implantation of fibrin hydrogels containing neural progenitor cells resulted in some functional recovery in SCI rats. Ballios et al. demonstrated greater cell survival after transplantation in a hyaluronan/methylcellulose hydrogel compared to saline [48]. OEG support and guide axon elongation in their native olfactory system and have shown promise after spinal cord injury as well $[49,50]$. OEG transplanted immediately or up to 2 months after SCI in rats resulted in functional recovery and/or tissue regeneration [51,52]. Significantly,

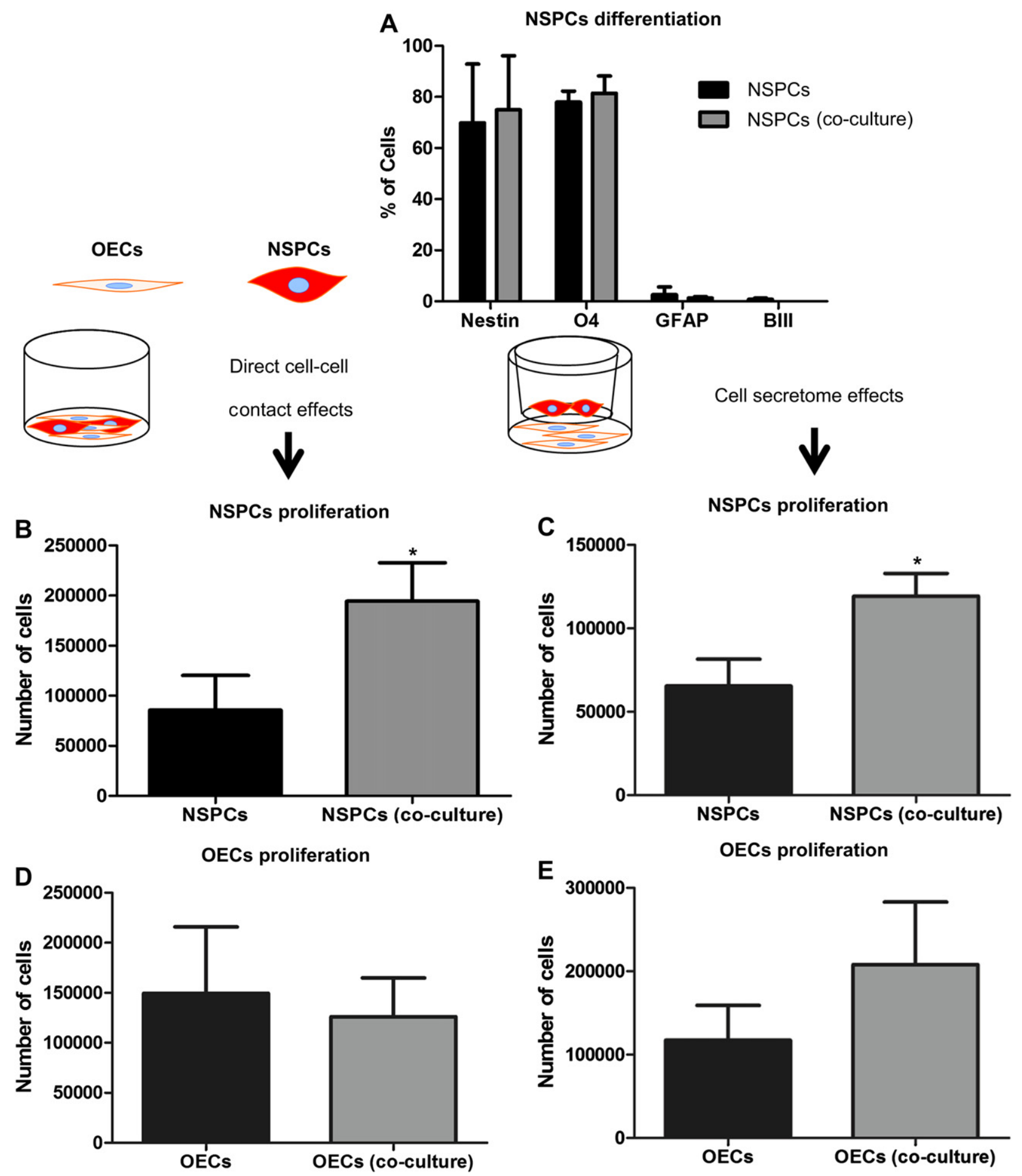

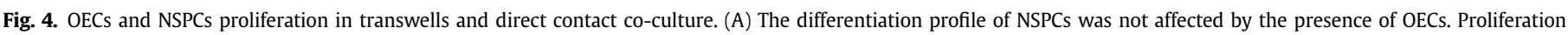

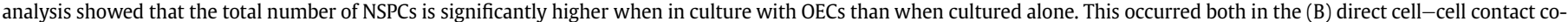

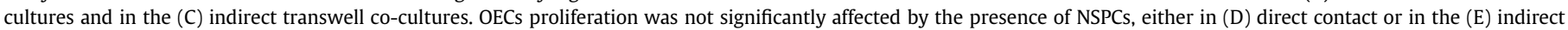
transwell co-culture. Values are shown as mean \pm standard deviation ( $n=3$ independent studies of a minimum of 4000 cells counted per study, $\left.{ }^{*} p<0.05\right)$. 

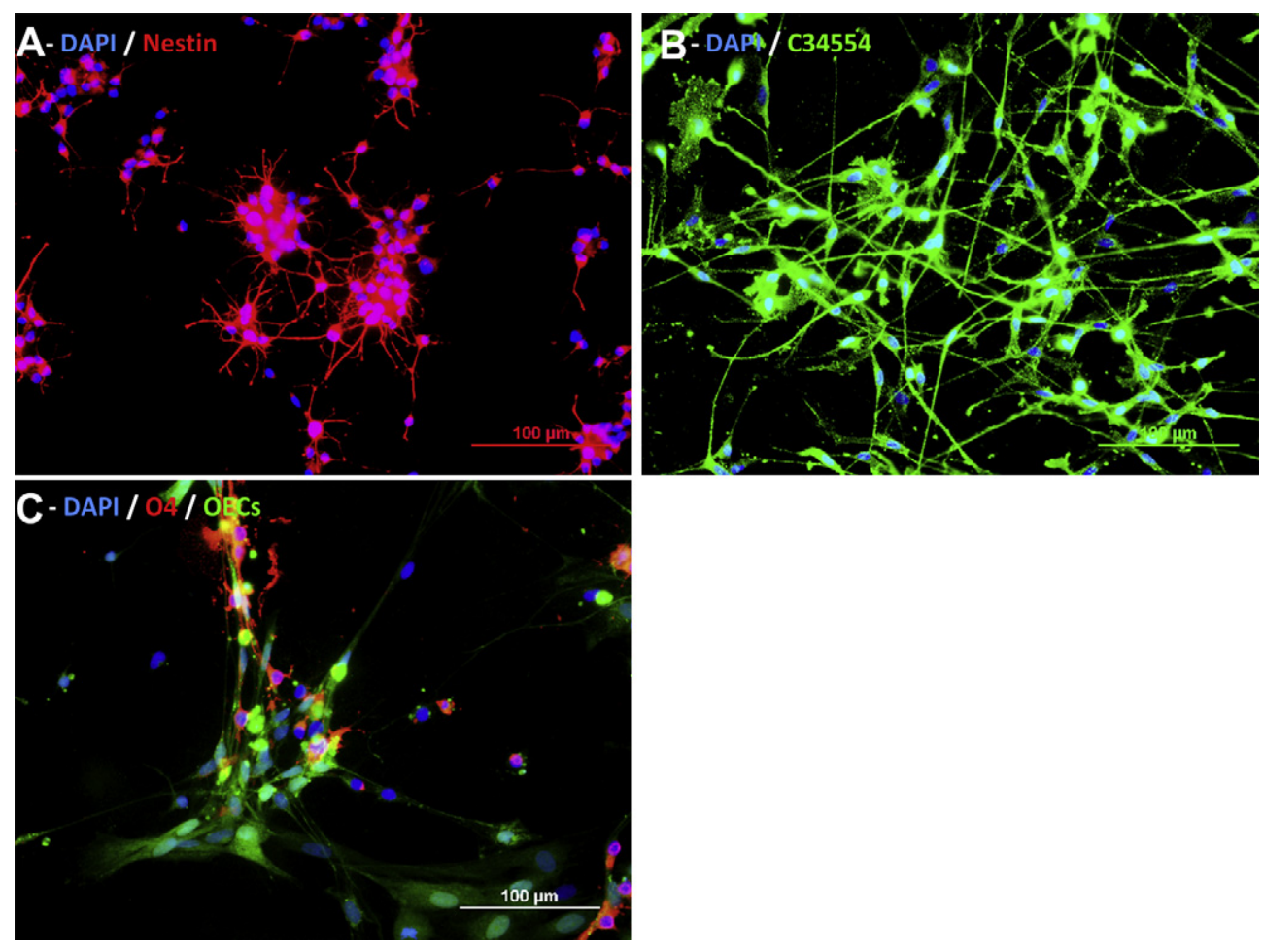

Fig. 5. OECs and NSPCs interact with each other during co-culture. (A) Monocultures of NSPCs and (B) Monocultures OECs served as controls. (C) OECs (green, CFSE 34554) and NSPCs (red, 04) appear to be closely associated when the cells are cultured together in direct contact. NSPCs were identified by immunocytochemistry and nuclei are counterstained with DAPI (blue). (For interpretation of the references to color in this figure legend, the reader is referred to the web version of this article.)
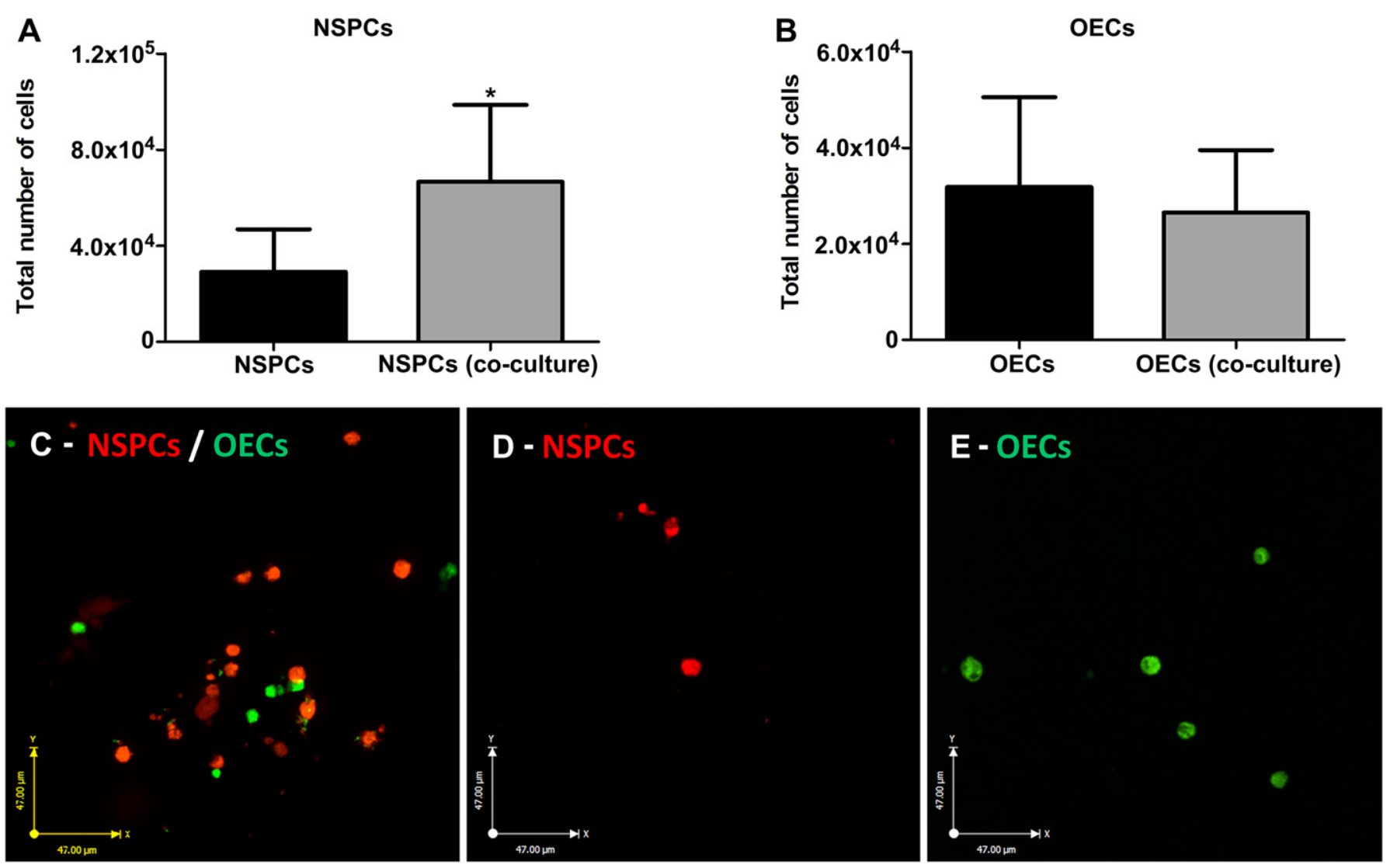

Fig. 6. Co-culture between OECs and NSPCs in the GG-GRGDS hydrogel. (A) After counting the cells, it was possible to observe that the number of NSPCs was significantly higher when co-cultured with OECs than when cultured alone. (B) In contrast, OEC proliferation was unaffected by the presence of NSPCs in culture. (C) Co-cultures of NSPCs (red, DDAO-SE 34553) and OECs (green, CFSE 34554) suggested some interaction between the two cell types as observed by confocal microscopy. (D) NSPCS and (E) OECs were cultured alone to serve as controls. Values are shown as mean \pm standard deviation $\left(n=3\right.$ independent experiments of 200 cells counted per experiment, $\left.{ }^{*} p<0.05\right)$. (For interpretation of the references to color in this figure legend, the reader is referred to the web version of this article.) 
OEG have been tested in three separate clinical trials $[30,53,54]$; however, only very modest (if any) motor improvements were observed. Despite the promise for cell therapy, with OEG or NSPCs, the functional recovery has been modest, underlining the need for innovative strategies, such as the combined transplantation of OEG and NSPCs in a GG-GRGDS hydrogels. The simplicity and broad applicability of the Diels-Alder click chemistry can be easily extended to other biomolecules to further promote NSPC differentiation for greater integration with the host tissue. This combination strategy could be powerful, with OEG and gellan gum providing a cellular pathway on which NSPCs could differentiate, thereby replacing the damaged tissue and achieving greater functional repair.

\section{Conclusions}

Using well-established Diels-Alder click chemistry, we immobilized the GRGDS fibronectin-derived peptide to gellan gum hydrogels, which promoted greater adhesion and proliferation of neural stem/progenitor cells than gellan gum controls. Moreover, NSPCs cocultured with olfactory ensheathing glia showed greater survival and outgrowth than NSPCs cultured alone. These results suggest that the combined use of NSPCs and OEG with bioengineered GG-GRGDS hydrogels may be beneficial in regenerative medicine cell transplantation strategies to promote repair after spinal cord injury.

\section{Acknowledgments}

We are grateful to Dr Ying Fang Chen for the isolation and propagation of neural stem/progenitor cells, Dr Shawn Owen for assistance with chemical modification of gellan gum and to Rey Interior from Advanced Protein Technology Centre at Toronto's Hospital for Sick Children for amino acid analyses. We acknowledge funding from: the Canadian Institute of Health Research (MSS); the Ontario Neurotrauma Foundation and Stem Cell Network (MJC); the Ontario Ministry of Research and Innovation (post-doctoral fellowship to RYT); and the Portuguese Foundation for Science and Technology (doctoral fellowship to NAS - SFRH/BD/40684/2007; Science 2007 Program - António J. Salgado; Grant No. PTDC/SAU-BMA/114059/2009).

\section{References}

[1] Bracken MB. Methylprednisolone and acute spinal cord injury: an update of the randomized evidence. Spine 2001;26:S47-54.

[2] Hurlbert RJ. Methylprednisolone for acute spinal cord injury: an inappropriate standard of care. J Neurosurg 2000;93:1-7.

[3] Casha S. Minocycline and perfusion pressure augmentation in acute spinal cord injury. NCT00559494, http://clinicaltrials.gov/ct2/show/NCT00559494? term $=$ NCT00559494\&rank=1; 2008. Clinicaltrials.gov.

[4] Novartis. Acute safety, tolerability, feasibility and phermacokinetics of intrath. administered ATI355 in patients with acute SCI. NCT00406016, http:// clinicaltrials.gov/ct2/show/NCT00406016?term $=$ NCT00406016\&rank=1; 2011. Clinicaltrials.gov.

[5] Geron. Safety study of GRNOPC1 in spinal cord injury. NCT01217008. Clinicaltrials.gov, http://clinicaltrials.gov/ct2/show/NCT01217008?term=NCT01217008 \&rank=1; 2012.

[6] Lu J, Féron F, Mackay-Sim A, Waite PME. Olfactory ensheathing cells promote locomotor recovery after delayed transplantation into transected spinal cord Brain 2002;125:14-21.

[7] Li Y, Field PM, Raisman G. Repair of adult rat corticospinal tract by transplants of olfactory ensheathing cells. Science 1997;277:2000-2.

[8] Kim H, Zahir T, Tator CH, Shoichet MS. Effects of dibutyryl cyclic-AMP on survival and neuronal differentiation of neural stem/progenitor cells transplanted into spinal cord injured rats. PLoS ONE 2011;6:e21744.

[9] Pal R, Gopinath C, Rao NM, Banerjee P, Krishnamoorthy V, Venkataramana NK et al. Functional recovery after transplantation of bone marrow-derived human mesenchymal stromal cells in a rat model of spinal cord injury. Cytotherapy 2010;12:792-806.

[10] Arboleda D, Forostyak S, Jendelova P, Marekova D, Amemori T, Pivonkova H, et al. Transplantation of predifferentiated adipose-derived stromal cells for the treatment of spinal cord injury. Cell Mol Neurobiol; 2011:1-10.
[11] Doucette R. Glial influences on axonal growth in the primary olfactory system. Glia 1990;3:433-49.

[12] Ramón-Cueto A, Nieto-Sampedro M. Regeneration into the spinal cord of transected dorsal root axons is promoted by ensheathing glia transplants. Exp Neurol 1994;127:232-44.

[13] Woodhall E, West AK, Chuah MI. Cultured olfactory ensheathing cells express nerve growth factor, brain-derived neurotrophic factor, glia cell line-derived neurotrophic factor and their receptors. Mol Brain Res 2001;88:203-13.

[14] Karimi-Abdolrezaee S, Eftekharpour E, Wang J, Morshead CM, Fehlings MG. Delayed transplantation of adult neural precursor cells promotes remyelination and functional neurological recovery after spinal cord injury. J Neurosci 2006;26:3377-89.

[15] McDonald JW, Liu X-Z, Qu Y, Liu S, Mickey SK, Turetsky D, et al. Transplanted embryonic stem cells survive, differentiate and promote recovery in injured rat spinal cord. Nat Med 1999;5:1410-2.

[16] Robey TE, Saiget MK, Reinecke H, Murry CE. Systems approaches to preventing transplanted cell death in cardiac repair. J Mol Cell Cardiol 2008;45: $567-81$.

[17] Zvibel I, Smets F, Soriano H. Anoikis: roadblock to cell transplantation? Cell Transplant 2002;11:621-30.

[18] Moorhouse R, Colegrove GT, Sandford PA, Baird JK, Kang KS. PS-60: a new gelforming polysaccharide. In: Brant DA, editor. Solution properties of polysaccharides. Washington: Am Chem Soc; 1981. p. 111-24.

[19] Kubo W, Miyazaki S, Attwood D. Oral sustained delivery of paracetamol from in situ-gelling gellan and sodium alginate formulations. Int J Pharmaceut 2003;258:55-64.

[20] Oliveira JT, Gardel LS, Rada T, Martins L, Gomes ME, Reis RL. Injectable gellan gum hydrogels with autologous cells for the treatment of rabbit articular cartilage defects. J Orthop Res 2010;28:1193-9.

[21] Silva-Correia J, Oliveira JM, Caridade SG, Oliveira JT, Sousa RA, Mano JF, et al. Gellan gum-based hydrogels for intervertebral disc tissue-engineering applications. J Tissue Eng Regen M 2011;5:e97-107.

[22] Luo Y, Shoichet MS. A photolabile hydrogel for guided three-dimensional cell growth and migration. Nat Mater 2004;3:249-53.

[23] Tong YW, Shoichet MS. Enhancing the neuronal interaction on fluoropolymer surfaces with mixed peptides or spacer group linkers. Biomaterials 2001;22: 1029-34.

[24] Yu TT, Shoichet MS. Guided cell adhesion and outgrowth in peptide-modified channels for neural tissue engineering. Biomaterials 2005;26:1507-14.

[25] Adams JC, Watt FM. Regulation of development and differentiation by the extracellular matrix. Development 1993;117:1183-98.

[26] Schwarz M, Mitchell M, Emerson D. Reconstituted basement membrane enhances neurite outgrowth in PC12 cells induced by nerve growth factor. Cell Growth Differ 1990;1:313-8.

[27] Cooke MJ, Vulic K, Shoichet MS. Design of biomaterials to enhance stem cell survival when transplanted into the damaged central nervous system. Soft Matter 2010;6:4988-98.

[28] Kim H, Cooke MJ, Shoichet MS. Creating permissive microenvironments for stem cell transplantation into the central nervous system. Trends Biotechnol 2012;30:55-63.

[29] Ayuso-Sacido A, Roy NS, Schwartz TH, Greenfield JP, Boockvar JA. Long-term expansion of adult human brain subventricular zone precursors. Neurosurgery 2008;62:223-9.

[30] Feron F, Perry C, Cochrane J, Licina P, Nowitzke A, Urquhart S, et al. Autologous olfactory ensheathing cell transplantation in human spinal cord injury. Brain 2005;128:2951-60.

[31] Wellings DA, Atherton E. Standard fmoc protocols. In: Gregg BF, editor. Methods in enzymology. Academic Press; 1997. p. 44-67.

[32] Morshead CM, Reynolds BA, Craig CG, McBurney MW, Staines WA, Morassutti D, et al. Neural stem cells in the adult mammalian forebrain: a relatively quiescent subpopulation of subependymal cells. Neuron 1994;13:1071-82.

[33] Cao L, Mu L, Oiu Y, Su Z, Zhu Y, Gao L, et al. Diffusible, membrane-bound, and extracellular matrix factors from olfactory ensheathing cells have different effects on the self-renewing and differentiating properties of neural stem cells. Brain Res 2010;1359:56-66.

[34] Silva NA, Salgado AJ, Sousa RA, Oliveira JT, Pedro AJ, Leite-Almeida H, et al. Development characterization of a novel hybrid tissue engineering based scaffold for spinal cord injury repair. Tissue Eng Part A 2010;16:45-54.

[35] Coutinho DF, Sant SV, Shin H, Oliveira JT, Gomes ME, Neves NM, et al Modified gellan gum hydrogels with tunable physical and mechanical properties. Biomaterials 2010;31:7494-502.

[36] Lévesque SG, Shoichet MS. Synthesis of cell-adhesive dextran hydrogels and macroporous scaffolds. Biomaterials 2006;27:5277-85.

[37] Fink H, Ahrenstedt L, Bodin A, Brumer H, Gatenholm P, Krettek A, et al. Bacterial cellulose modified with xyloglucan bearing the adhesion peptide RGD promotes endothelial cell adhesion and metabolism-a promising modification for vascular grafts. J Tissue Eng Regen M 2011;5: 454-63.

[38] Aizawa Y, Wylie R, Shoichet M. Endothelial cell guidance in 3D patterned scaffolds. Adv Mater 2010;22:4831-5.

[39] Leipzig ND, Wylie RG, Kim H, Shoichet MS. Differentiation of neural stem cells in three-dimensional growth factor-immobilized chitosan hydrogel scaffolds. Biomaterials 2011;32:57-64.

[40] Mackay-Sim A, Chuah MI. Neurotrophic factors in the primary olfactory pathway. Prog Neurobiol 2000;62:527-59. 
[41] Cattaneo E, McKay R. Proliferation and differentiation of neuronal stem cells regulated by nerve growth factor. Nature 1990;347:762-5.

[42] Tropepe V, Sibilia M, Ciruna BG, Rossant J, Wagner EF, van der Kooy D. Distinct neural stem cells proliferate in response to EGF and FGF in the developing mouse telencephalon. Dev Biol 1999;208:166-88.

[43] Caldwell M, He X, Wilkie N, Pollack S, Marshall G, Wafford K, et al. Growth factors regulate the survival and fate of cells derived from human neurospheres. Nat Biotechnol 2001;19:475-9.

[44] Steinke A, Meier-Stiegen S, Drenckhahn D, Asan E. Molecular composition of tight and adherens junctions in the rat olfactory epithelium and fila. Histochem Cell Biol 2008;130:339-61.

[45] Gascon E, Vutskits L, Kiss JZ. The role of PSA-NCAM in adult neurogenesis. In: Berezin V, editor. Structure and function of the neural cell adhesion molecule NCAM. New York: Springer; 2010. p. 127-36.

[46] Cummings BJ, Uchida N, Tamaki SJ, Salazar DL, Hooshmand M, Summers R, et al. Human neural stem cells differentiate and promote locomotor recovery in spinal cord-injured mice. P Natl Acad Sci U S A 2005;102:14069-74.

[47] Johnson PJ, Tatara A, McCreedy DA, Shiu A, Sakiyama-Elbert SE. Tissue-engineered fibrin scaffolds containing neural progenitors enhance functional recovery in a subacute model of SCI. Soft Matter 2010;6:5127-37.
[48] Ballios BG, Cooke MJ, van der Kooy D, Shoichet MS. A hydrogel-based stem cell delivery system to treat retinal degenerative diseases. Biomaterials 2010;31: 2555-64.

49] Ramón-Cueto A, Avila J. Olfactory ensheathing glia: properties and function. Brain Res Bull 1998;46:175-87.

[50] Kubasak MD, Jindrich DL, Zhong H, Takeoka A, McFarland KC, Muñoz-Quiles C et al. OEG implantation and step training enhance hindlimb-stepping ability in adult spinal transected rats. Brain 2008;131:264-76.

[51] Li Y, Decherchi P, Raisman G. Transplantation of olfactory ensheathing cells into spinal cord lesions restores breathing and climbing. J Neurosci 2003;23: 727-31.

[52] Keyvan-Fouladi N, Raisman G, Li Y. Functional repair of the corticospinal tract by delayed transplantation of olfactory ensheathing cells in adult rats. J Neurosci 2003;23:9428-34

[53] Lima C, Pratas-Vital J, Escada P, Hasse-Ferreira A, Capucho C, Peduzzi JD. Olfactory mucosa autografts in human spinal cord injury: a pilot clinical study. J Spinal Cord Med 2006;29:191-203.

[54] Dobkin BH, Curt A, Guest J. Cellular transplants in china: observational study from the largest human experiment in chronic spinal cord injury. Neurorehab Neural Re 2006;20:5-13. 